Check for updates

Cite this: RSC Adv., 2017, 7, 55536

Received 26th September 2017 Accepted 27th November 2017

DOI: 10.1039/c7ra10637h

rsc.li/rsc-advances

\title{
Graphene oxide enhanced, radiation cross-linked, vitamin E stabilized oxidation resistant UHMWPE with high hardness and tensile properties
}

\begin{abstract}
Wenchao Pang, (D) *a Jialiang Wu, ${ }^{a}$ Qifan Zhang ${ }^{b}$ and Guangfei Li ${ }^{\mathrm{b}}$
A method for enhancing the micro-hardness and tensile properties of cross-linked ultrahigh molecular weight polyethylene (UHMWPE) for total joint implants by radiation cross-linking after adding vitamin-E (VE) and graphene oxide (GO) was reported in this paper. Vitamin E was blended with UHMWPE powder at a concentration of $0.1 \mathrm{wt} \%$, followed by adding GO at a concentration of $0.5 \mathrm{wt} \%$ and subsequently irradiated with ${ }^{60} \mathrm{Co}$ gamma-rays at $100 \mathrm{kGy}$. The GO/VE/UHMWPE composite showed improved microhardness ( $8 \%)$, Young's modulus ( 28\%), yield stress $(\sim 33 \%)$ and fracture stress $(\sim 37 \%)$ in comparison with UHMWPE. The OI of irradiated UHMWPE decreased from 1.9 to 0.7 after blending with VE and the OI of irradiated VE/UHMWPE increased from 0.7 to 1.3 after filling with GO. In addition, the addition of GO further reduced the gel content.
\end{abstract}

\section{Introduction}

Cross-linked UHMWPE is widely used as a total joint arthroplasty bearing material because of its good resistance to wear, which can stabilize periprosthetic osteolysis and aseptic loosening during long-term service in the human body. ${ }^{1}$ However, a mass of free radicals is generated in both amorphous and crystalline phases during the irradiation process. The free radicals not only reassociate with each other to form a network structure, but also remain for a long time and cause oxidation in highly cross-linked UHMWPE by migrating into the amorphous phase and reacting with diffused oxygen. ${ }^{2,3}$ Melt recrystallization has been employed to stabilize the residual free radicals. Although this thermal stabilization process decreases the free radicals effectively and maintains the resistance to wear, the mechanical properties, such as tensile properties, are deteriorated because of the reduced crystallinity. ${ }^{4}$ Annealing treatment is a method to retain the good mechanical properties of the material after irradiation. ${ }^{5}$ Vitamin-E is also employed to enhance the resistance to oxidation. Vitamin-E stabilized the irradiated UHMWPE, which has avoided the decrease in crystallinity and mechanical properties compares to melting treated UHMWPE. ${ }^{6}$ However, there is no significant effect to the microhardness and tensile properties of UHMWPE with the incorporation of vitamin-E $(0.1-0.4 \mathrm{wt} \%)^{7-9}$ In addition, the efficiency of crosslinking and wear resistance dramatically decreases with the filler of high content vitamin-E. ${ }^{7}$

${ }^{a}$ School of Mechatronic Engineering, Qilu Institute of Technology, Jinan 250200, Shandong, China. E-mail: pangwenchaogg@sina.com

${ }^{b}$ School of Mechanical Engineering, Jiangnan University, Wuxi 214122, Jiangsu, China
In order to solve those problems, the researchers have devoted a lot of efforts to balance the wear resistance, oxidation resistance and mechanical properties. Oral et al. ${ }^{10}$ limit distribution of crosslinking density in the implant though controlling the concentration of vitamin-E, so that high crosslink density on the surface is remained and low crosslink density on the bulk is controlled. The study has shown that this method improved the fatigue strength and wear resistance. Fu et al. ${ }^{11}$ study the effect of high temperature melting on the irradiated VE/UHMWPE blend. It is demonstrated that this method improves its wear and impact strength, but there is no effect on tensile properties of the polymer. Although the above techniques enhance the wear resistance and impact strength to some extent, they have some disadvantages such as the expensive cost and complication of process. Therefore, there is a crying need to find an advanced technology to fabricate new UHMWPE composite with excellent mechanical properties, well wear resistance and oxidation resistance.

Graphene oxide (GO), a functionalization of graphene, with excellent mechanical, ${ }^{12}$ thermal properties, ${ }^{13}$ and biocompatibility, ${ }^{14}$ has been widely used to enforce polymer properties. ${ }^{15-19}$ In our previous study ${ }^{16}$ graphene oxide (GO) is used as reinforcement to enhance the mechanical properties of UHMWPE. It is demonstrated that GO could enhance its micro-hardness and impact properties with low concentration of GO. Chen et al. ${ }^{17}$ Tai et al. ${ }^{18}$ and Suñer et al. ${ }^{19}$ also demonstrate that GO could improve the tensile properties, micro-hardness and resistance to wear of UHMWPE. Although researchers spend a lot of energy in GO/UHMWPE composites, the study of GO enhanced vitamin E-stabilized irradiated UHMWPE composite is rarely reported. Different from our previous study which just focuses on the effect of adding GO into UHMWPE, ${ }^{16}$ the GO/ 
UHMWPE composite is exposed to irradiation treatment and VE is added to improve the oxidation resistance of irradiated composite in this paper.

Therefore, we propose to fill $0.5 \mathrm{wt} \%$ GO into $0.1 \mathrm{wt} \%$ vitamin E-stabilized UHMWPE blend prior to radiation crosslinking to further enhance its mechanical properties without sacrificing their resistance to oxidation. In order to confirm whether the mechanical properties of irradiated $\mathrm{GO} / \mathrm{VE} /$ UHMWPE composite can be enhanced or not, tensile and micro-hardness test are performed. Since mechanical strength and oxidation are two critical factors to joint implant material, we also develop standard and aggressive accelerated aging test to study the molecular structure and oxidation of the irradiated GO/VE/UHMWPE composite. In addition, we also study the dispersion of GO, the degree of crystallinity and gel content, which are the three critical factors to the tensile performance and micro-hardness of the polymer composites.

\section{Materials and methods}

\subsection{Preparation of irradiated GO/VE/UHMWPE composite}

Ultrahigh molecular weight polyethylene powder was supplied by the Shanghai Research Institute of Chemical Industry, China. High-purity graphite powder $(99.9 \%, 325$ mesh) was purchased from Qingdao Jinrilai graphite Co. Ltd., China. Other reagents were of analytical grade and were commercially available.

Graphene oxide (GO) was prepared through the modified Hummer's methods ${ }^{20}$ The mixture of $1 \mathrm{~g}$ graphite, $2 \mathrm{~g} \mathrm{NaNO}$ and $70 \mathrm{ml}$ concentrated $\mathrm{H}_{2} \mathrm{SO}_{4}$ was stirred for $1 \mathrm{~h}$ in ice bath. Then $6 \mathrm{~g}$ $\mathrm{KMnO}_{4}$ was slowly added to the mixture and the mixture was kept stirring for $2 \mathrm{~h}$ in ice bath, and then kept stirring for $1 \mathrm{~h}$ at $35^{\circ} \mathrm{C}$. $100 \mathrm{ml}$ deionized water was slowly added into the mixture, and then there was red violet gas produced. After stirring for $0.5 \mathrm{~h}$, the mixture was added into $10 \mathrm{ml} \mathrm{H}_{2} \mathrm{O}_{2}$ and then cooled to room temperature. The suspension was removed from the prepared thickened liquid by centrifuge and then it was washed with $10 \%$ $\mathrm{HCl}$ solution for three times. And it was washed with deionized water several times until $\mathrm{pH}$ was close to neutral. The resulting viscous object was dried at $60{ }^{\circ} \mathrm{C}$ for about $24 \mathrm{~h}$ under vacuum environment and the required GO was obtained.

The GO/VE/UHMWPE composite was prepared by liquid ball milling mixing and compression molding process, followed by irradiation in vacuum environment. Based on our previous study ${ }^{16}$ and other literatures, ${ }^{17,19}$ the overall performance of GO/ UHMWPE composites could achieve the optimal effect with the incorporation of $0.5 \mathrm{wt} \% \mathrm{GO}$. The details of sample preparation were as follows: firstly, $0.5 \mathrm{~g}$ GO powder and $0.1 \mathrm{~g}$ VE were dispersed in $200 \mathrm{ml}$ alcohol solution followed by ultrasonic for $0.5 \mathrm{~h}$. Then, $99.4 \mathrm{~g}$ UHMWPE powders were filled into the dispersed solution and then the solution was treated by ultrasonic for $0.5 \mathrm{~h}$. Subsequently, the mixture solution was mixed by ball milling at the speed of $400 \mathrm{rpm}$ for $2 \mathrm{~h}$ and then kept in a water bath at $60^{\circ} \mathrm{C}$ until the solvent was completely dry. Next, the dried mixture powders were further ball-mixed for $2 \mathrm{~h}$, and prepressed at the pressure of $10 \mathrm{MPa}$ for $0.25 \mathrm{~h}$ followed by heating for $2 \mathrm{~h}$ at $180{ }^{\circ} \mathrm{C}$, and then cooled down to room temperature under $15 \mathrm{MPa}$ for about $3 \mathrm{~h}$ in air. Many studies report that vacuum packaging is effective at minimizing polymer damage due to oxidation. ${ }^{21-23}$ So, the prepared UHMWPE, VE/UHMWPE and GO/VE/UHMWPE composite were packed using vacuum foil packing bags and then irradiated by ${ }^{60} \mathrm{Co}$ gamma-rays (WuXi EL PONT Radiation Technology Co., Ltd) with a dose of $100 \pm 8 \mathrm{kGy}$ at room temperature.

\subsection{Characterization}

Molecular structure was studied by Fourier transform infrared (FT-IR) spectrum, which was performed by Bruker ALPHA FT-IR spectrometer (Bruker Instruments Corporation, Germany). In order to investigate the oxidation stability of the irradiated $\mathrm{GO} /$ VE/UHMWPE composite, accelerated aging process was performed by electric thermostatic drying oven (Shanghai Boxun Industry \& Commerce Co., Ltd) at $80{ }^{\circ} \mathrm{C}$ for 21 days in air according to ASTM F2003-02 (2015). The resistance to oxidation was measured via Oxidation Index (OI), which was computed by the following equation: ${ }^{11}$

$$
\mathrm{OI}=\frac{A_{1680-1780 \mathrm{~cm}^{-1}}}{A_{1330-1390 \mathrm{~cm}^{-1}}} .
$$

The cryogenic fracture morphology of the composite was characterized by Scanning Electron Microscopy. Thermal weight loss was studied by means of a thermogravimetric analyzer (TGA, TGA/1, Switzerland) with temperature ranging from 50 to $800{ }^{\circ} \mathrm{C}$ at a rate of $20{ }^{\circ} \mathrm{C} \mathrm{min}{ }^{-1}$ under a nitrogen atmosphere. The crystallinity of the irradiated and nonirradiated GO/VE/UHMWPE composite was studied by TA Q2000 (TA Instruments Corporation, USA) under nitrogen atmosphere. The crystallinity of samples was computed on basis of the following equation:

$$
X_{\mathrm{C}}=\frac{\Delta H}{(1-\varnothing) \Delta H^{0}}
$$

where $\varnothing$ is the content of filler into samples, $\Delta H$ is the melting enthalpy of samples which can be obtained from DSC curves and $\Delta H^{0}$ is the melting enthalpy of a $100 \%$ crystalline UHMWPE normalized by $293 \mathrm{~J} \mathrm{~g}^{-1}$. $^{17}$ The gel content test was performed in terms of the standard of ASTM D 2765-01. Tensile tests specimens were fabricated in terms of the standard of ASTM D638. Tensile sample sizes were $33 \mathrm{~mm}$ in effective length, $6 \mathrm{~mm}$ in width and $3.2 \mathrm{~mm}$ in thickness (Fig. 1a). The dumbbell-shaped tensile samples were tested at the speed of $5 \mathrm{~mm} \min ^{-1}$ on a tensile machine (WDW-200, Ji'nan Shijin Group Co. Ltd., China). The tensile properties (yield strength, fracture strength and Young's modulus) were calculated according to the standard of ASTM D-638. The micro-hardness tests were performed on a universal tribometer (Rtec instruments, USA), as shown in Fig. 1b. The ball indentation hardness was tested on the basis of the standard of ISO2039-73 (indenter: $5 \mathrm{~mm}$ diameter $\mathrm{Si}_{3} \mathrm{~N}_{4}$ ball; initial load: $9.8 \mathrm{~N}$; test load: $132 \mathrm{~N}$ ). The ball indentation hardness was measured in terms of the following equation:

$$
H=\frac{P_{\max }}{\pi D h_{\max }}
$$



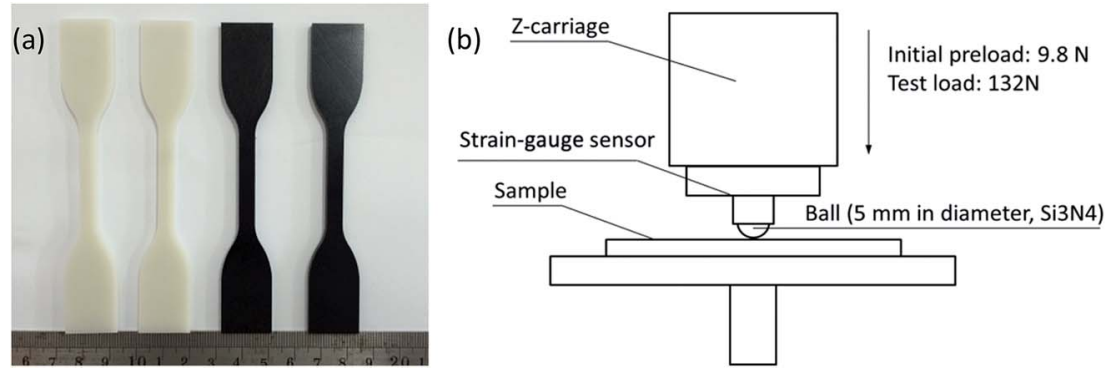

Fig. 1 Image of (a) tensile specimens of composite: white materials are UHMWPE and black materials are 0.5\% GO/UHMWPE composites and (b) diagram of indentation hardness test.

where $P_{\max }$ is the maximum test force, $D$ is the diameter of the test ball, and $h_{\max }$ is the maximal indentation depth.

\subsection{Statistical analysis}

All the data obtained in the study were expressed as the mean of at least three replicate determinations. Analysis of variance (ANOVA) was performed using the software SPSS16.0 (SPSS Inc., Chicago, IL, USA) with one-way analysis of variance (ANOVA) and Duncan's multiple-range test. $P<0.05$ was used to define the significance of differences between the samples.

\section{Results and discussion}

\subsection{Molecular structure and oxidation index (OI)}

Molecular structure and oxidation index of all the samples are studied by FT-IR. As can be seen in the spectrum of vitamin-E (Fig. 2a), methyl asymmetric and symmetric bending peaks appear at $1466 \mathrm{~cm}^{-1}$ and $1378 \mathrm{~cm}^{-1}$ respectively; $\mathrm{C}-\mathrm{O}$ stretching of the phenol appears at $1260 \mathrm{~cm}^{-1}$; ether group appears at $1093 \mathrm{~cm}^{-1}$; absorption peak of $\mathrm{C}-\mathrm{H}$ stretching appears at $2847 \mathrm{~cm}^{-1}$ and $2918 \mathrm{~cm}^{-1}$ (Fig. 2a). However, it is difficult to identify main absorption bands of vitamin- $\mathrm{E}$ in the same spectrum range of VE/UHMWPE and GO/VE/UHMWPE, due to the low concentration of vitamin-E. Fig. $2 \mathrm{~b}$ shows the spectrums of non-irradiated and irradiated GO. In the spectrum of nonirradiated $\mathrm{GO}$, the $\mathrm{O}-\mathrm{H}$ stretching vibrations bonds appear at $3420 \mathrm{~cm}^{-1}$, the $\mathrm{C}=\mathrm{O}$ stretching vibration bonds and unoxidized sp $\mathrm{sp}^{2} \mathrm{C}-\mathrm{C}$ bonds appear at $1725 \mathrm{~cm}^{-1}$ and $1627 \mathrm{~cm}^{-1}$, the $\mathrm{C}-\mathrm{O}$ vibration bonds appear at $1050 \mathrm{~cm}^{-1}$, respectively. It is shown that a great deal of oxygen containing polarity groups were existed on the surface of GO. However, the intensities of the bonds are reduced to some extent after irradiation. Irradiation could result in break of $\mathrm{C}=\mathrm{O}$ and $\mathrm{C}-\mathrm{O}$ bond, so the containing-oxidation groups may be decreased in the irradiation process. In addition, no further differences are observed.

As shown in Fig. 2c, the location of the primary absorption peak of irradiated GO/VE/UHMWPE composite has no significant change compared to that of irradiated VE/UHMWPE composite. Absorption peak of $\mathrm{C}-\mathrm{H}$ stretching appear at $2840 \mathrm{~cm}^{-1}$ and $2918 \mathrm{~cm}^{-1}$, the bending peak of $\mathrm{C}-\mathrm{H}$ bonds appears at $1462 \mathrm{~cm}^{-1}$, the $\mathrm{C}=\mathrm{C}$ stretching bonds appear at around $1650 \mathrm{~cm}^{-1}$, the $\mathrm{CH}_{2}$ peak appear at $720 \mathrm{~cm}^{-1}$, which indicated that the filler of GO led no pronounced effect to the molecular structure of irradiated VE/UHMWPE blend. However, the intensities of the major absorption peak are increased dramatically, attribute to the conjugation effect of $\mathrm{C}-\mathrm{C}$ bonds and polar functional groups on the surface of GO. Moreover, there is a weak peak appears around $1715 \mathrm{~cm}^{-1}(\mathrm{C}=\mathrm{O})$ of irradiated GO/VE/UHMWPE compare to irradiated VE/ UHMWPE blend, indicating that GO is filled in the composite successfully.

It is known that irradiation could lead to oxidation on the surface of UHMWPE, accompany by decreasing of the mechanical properties and wear resistance. ${ }^{24}$ Although vitaminE could hinder the oxidation of UHMPWE, the resistance to oxidation of irradiated GO/VE/UHMWPE is not clearly yet. So, an accelerated aging test is performed to investigate the

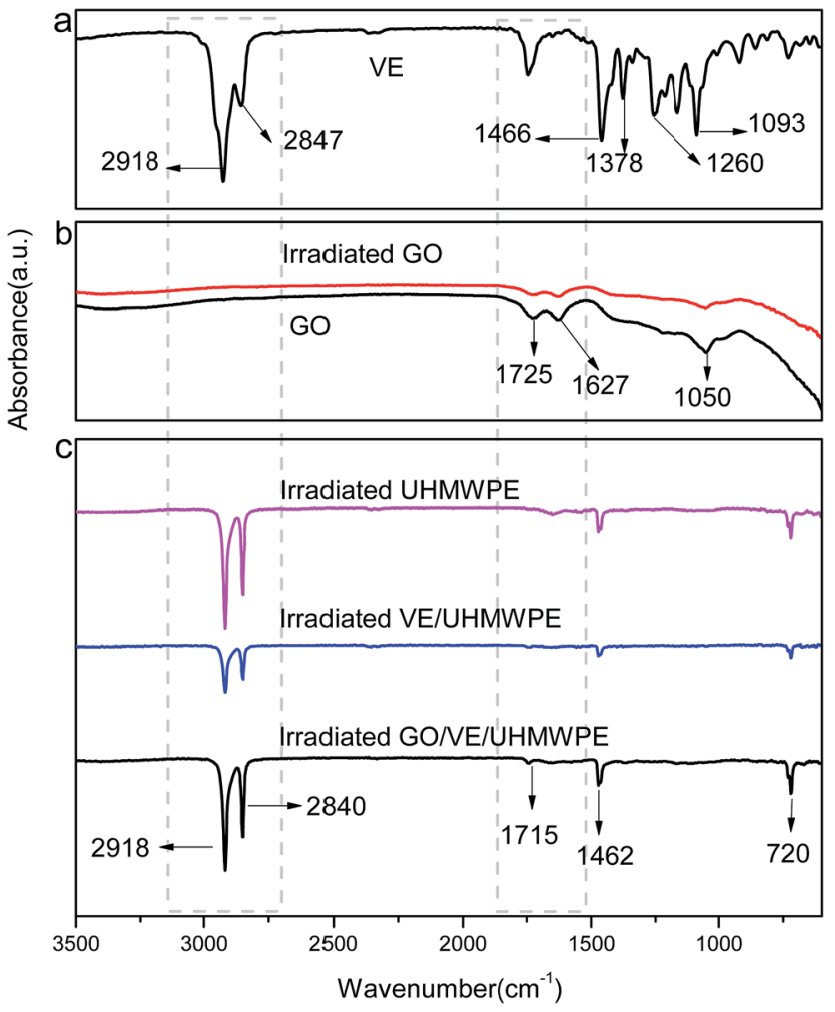

Fig. 2 FT-IR spectrums of (a) vitamin-E; (b) irradiated and non-irradiated GO; (c) irradiated GO/VE/UHMWPE composite. 


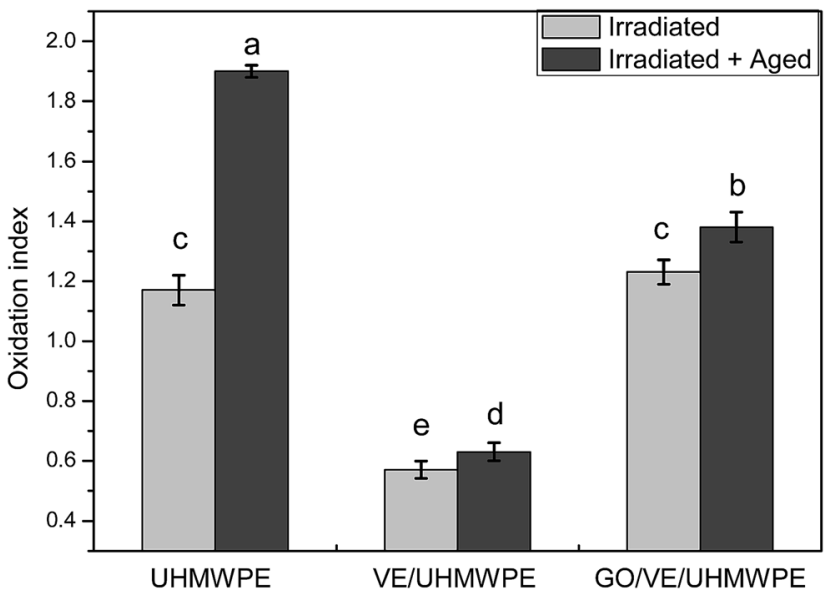

Fig. 3 Ol of irradiated and irradiated + aged UHMWPE composite. Error bars represent standard deviation. Different letters denote significant difference $(P<0.05)$.

oxidation resistance of the samples. The oxidation index of both aged and unaged samples is also measured on basis of FT-IR and the results are plotted in Fig. 3. The OI of irradiated but non-aged UHMWPE is relatively high. It may be caused by the oxidation in air during the process of hot pressing. The OI of irradiated UHMWPE before and after aging are $1.17 \pm 0.05$ and $1.90 \pm 0.02$ respectively for almost increasing by $62.39 \%$ due to aging, which shows irradiated UHMWPE has poor resistance to oxidation. The OI of irradiated VE/UHMWPE composite is $0.57 \pm 0.032$ and run up to $0.63 \pm 0.03$ after aging for increasing by $10.5 \%$ which is significantly lower than that of the virgin UHMWPE. When GO is filled into irradiated VE/UHMWPE blend, the OI of irradiated GO/VE/UHMWPE before and after aging are $1.23 \pm 0.041$ and $1.38 \pm 0.05$ respectively for increasing by $12.19 \%$ due to aging. It is similar to irradiated VE/UHMWPE, which indicates that the incorporation of GO has no dramatically effect to the resistance to oxidation. In other words, the irradiated GO/VE/UHMWPE composite has well resistance to oxidation due to the existence of vitamin-E. However, the OI of irradiated GO/VE/ UHMWPE composite before and after aging are higher than that of aged and irradiated VE/UHMWPE blend, which attribute to the abundant carbonyl groups on the surface of GO as discussed above.

\subsection{Fracture morphology}

The well dispersion of fillers in composites is an important prerequisite for its excellent mechanical properties. The SEM images of the cryogenic fractured surfaces of pure UHMWPE, VE/UHMWPE and GO/VE/UHMWPE are shown in Fig. 4. As shown in Fig. 4a, the fractured surface of pure UHMWPE is relatively flat and contains some cracks. It is indicated that there are slight air holes in the UHMWPE matrix during the hotpress process, which leads to insufficient bonding. For the VE/ UHMWPE blend, the fractured surface presents fibrosis, and the surface is also found to have large cavitation (Fig. 4b). In contrast to VE/UHMWPE blend, the fractured surface of GO/VE/ UHMWPE nanocomposite is relatively coarse when GO is incorporated into the composite (Fig. 4c). Meanwhile, it can be seen that the GO sheets are distributed uniformly across the whole VE/UHMWPE matrix without obvious clusters, which is significant for the mechanical performance of nanocomposites.

\subsection{Crystallinity analysis and thermal performance}

For the sake of characterizing the effect of GO to the thermal properties of irradiated GO/VE/UHMWPE, both irradiated and non-irradiated GO/VE/UHMWPE composite are tested. The melting temperature and the crystallinity of all the tested specimens are described in Table 1.

The results show that the filler of both GO and VE have no significant effect on the melting temperature of non-irradiated GO/VE/UHMWPE composite. Pang et al. ${ }^{16}$ and Chen et al. ${ }^{17}$ also reports that GO has slightly impact on melting temperature of GO/UHMWPE composites. After irradiation, the melting temperature of all the irradiated samples is increased slightly. GO, with larger specific surface area, is grafted to the molecular chain of VE/UHMWPE composite in irradiation treatment process and enhance the interaction force between $\mathrm{GO}$ and $\mathrm{VE} /$ UHMWPE matrix, which could increase the melting temperature of samples. Moreover, Premnath et al..$^{25}$ also demonstrates that the crosslink could hinder the melting process, especially with high dose irradiation.

In addition, the incorporation of GO dramatically increases the crystallinity of GO/VE/UHMWPE nanocomposite by $6.45 \%$, compared to VE/UHMWPE blend. This can attribute to the huge specific surface area of GO, which can acts as nucleation sites for crystallization. Therefore, many nucleation can growth together and form a larger scale of crystallite so rapidly that lead
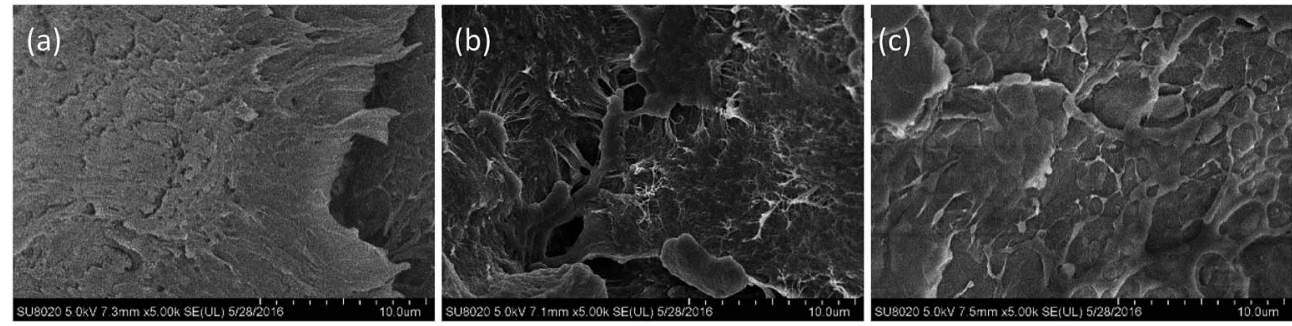

Fig. 4 SEM images of the cryogenic fractured surfaces: flat surface of pure UHMWPE (a), fibrotic surface of VE/UHMWPE blend (b) and coarse surface of GO/VE/UHMWPE nanocomposite (c). 
Table 1 Melting temperature and crystallinity of the studied nanocomposite ${ }^{a}$

\begin{tabular}{lll}
\hline Material & $T_{\mathrm{m}}\left({ }^{\circ} \mathrm{C}\right) \pm \mathrm{SD}$ & Crystallinity $(\%) \pm \mathrm{SD}$ \\
\hline UHMWPE & $133.9 \pm 0.1^{\mathrm{e}}$ & $50.6 \pm 1.2^{\mathrm{e}}$ \\
VE/UHMWPE & $134.3 \pm 0.2^{\mathrm{d}}$ & $50.9 \pm 1.1^{\mathrm{d}, \mathrm{e}}$ \\
GO/VE/UHMWPE & $133.1 \pm 0.2^{\mathrm{f}}$ & $54.2 \pm 1.0^{\mathrm{b}, \mathrm{c}}$ \\
Irradiated UHMWPE & $135.0 \pm 0.2^{\mathrm{c}}$ & $52.7 \pm 1.3^{\mathrm{c}, \mathrm{d}, \mathrm{e}}$ \\
Irradiated VE/UHMWPE & $134.9 \pm 0.3^{\mathrm{c}}$ & $53.1 \pm 1.4^{\mathrm{c}, \mathrm{d}}$ \\
Irradiated GO/VE/UHMWPE & $135.4 \pm 0.1^{\mathrm{b}}$ & $56.3 \pm 1.4^{\mathrm{b}}$
\end{tabular}

${ }^{a}$ SD: standard deviation. Means in the same column with different small superscript letters indicate significant difference at $P<0.05$.

to a higher degree of crystallinity. In addition, the irradiated GO/VE/UHMWPE composite has higher degree of crystallinity because the recrystallization of the molecular chain scission generated in the irradiation process. Meanwhile, the twodimensional wrinkled GO might hinder the mobility of chain scission, which lead to the chain scission assemble around GO surface and improve the probability of recrystallization.

In the thermal formation of the composites during industrial manufacture process, their properties may be affected due to the fracture of the molecular chain, which may be caused by plasticization molding under certain temperature conditions. Thermogravimetric analysis (TGA) is used to study the thermal stability of the composites, which is very necessary for polymer materials. The sample of TGA decomposition curves of pure UHMWPE showing demarcated temperatures $\left(T_{1}\right.$ and $\left.T_{2}\right)$ is shown in Fig. 5a. The initial decomposition temperature, $T_{1}$
(Fig. 5b), is characterized by the corresponding temperature of the weight loss of $5 \mathrm{wt} \%$ in the thermogravimetric analysis. The temperature of weight loss of $5 \mathrm{wt} \%\left(T_{1}\right)$ increases slightly with the addition of VE, which may be because the addition of VE increases the liquidity of UHMWPE molecular chain. The addition of GO slightly decreases the $T_{1}$ of VE/UHMWPE. The addition of $\mathrm{VE}$ increases the end of the linear weight loss temperature $\left(T_{2}\right)$ of UHMWPE and the addition of GO also increases the $T_{2}$ of VE/UHMWPE blend. The incorporation of VE and GO could slightly increase the thermal stability of UHMWPE. After irradiation treatment, thermal stability of all composites decreases due to the molecular chain of composites is severed and the length of molecular chain is decreased during irradiation treatment process. The results are in accordance with the study reported by Wang et al. ${ }^{26}$ which found that gamma ray and ion beam irradiation slightly decreased the thermal properties of UHMWPE. However, the influence of addition of VE/GO on the thermal performance is not significant $(P>0.05)$.

\subsection{Gel content}

Gel content measurements are performed to investigate the influence of the incorporation of GO on the crosslink density, which is associated to mechanical properties. The percentage gel contents of the studied irradiated-samples are shown in Fig. 6.

The gel content of irradiated UHMWPE is $90.25 \% \pm 1.5$ and decreases to $88.72 \% \pm 1.2$ after filling vitamin-E into UHMWPE matrix. It may be due to the property of stabilizing free radicals
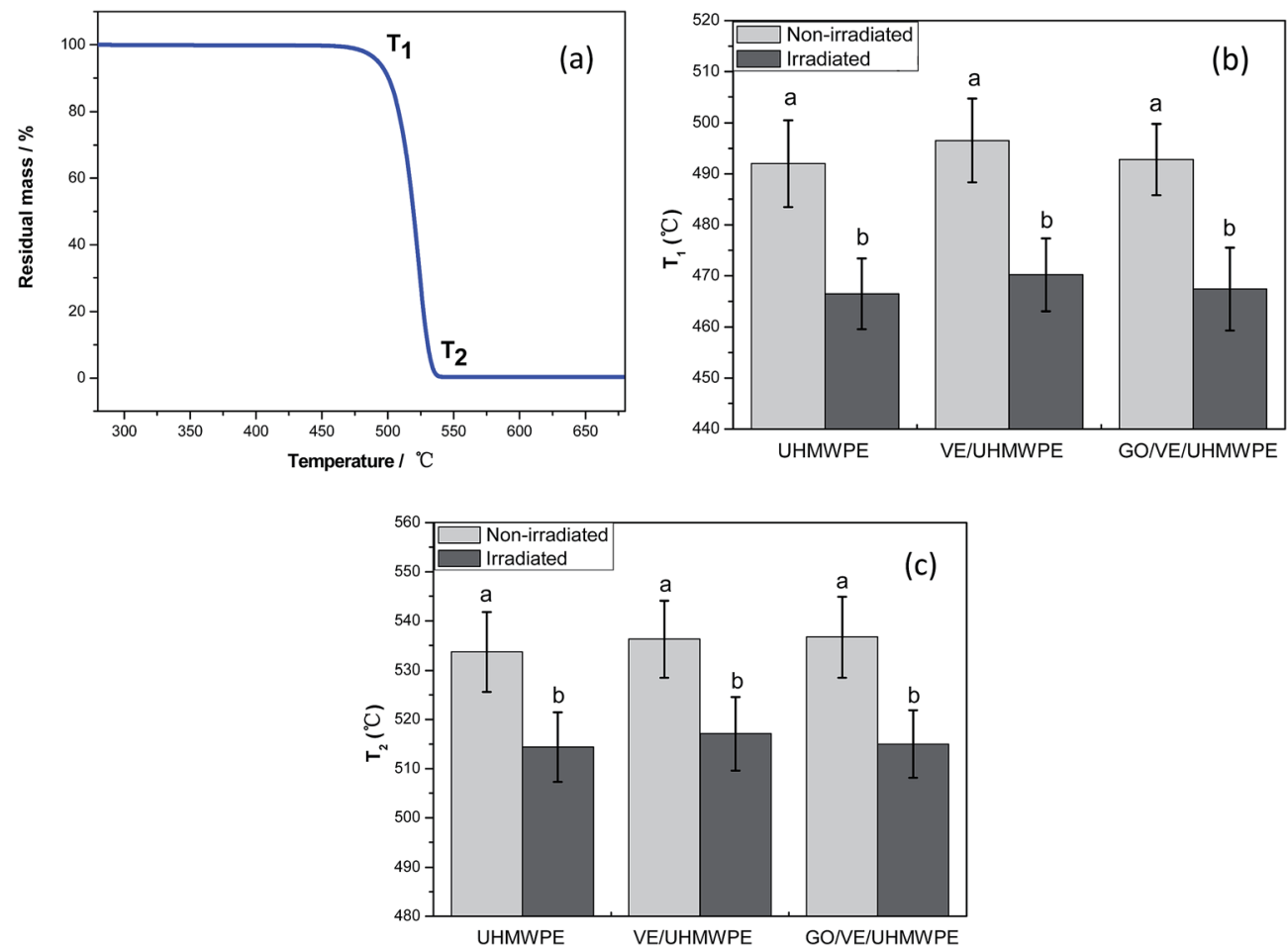

Fig. 5 Typical decomposition curve (a) of thermogravimetric analysis of UHMWPE and thermal stability parameters (b and c) of composite. Error bars represent standard deviation. Different letters denote significant difference $(P<0.05)$. 


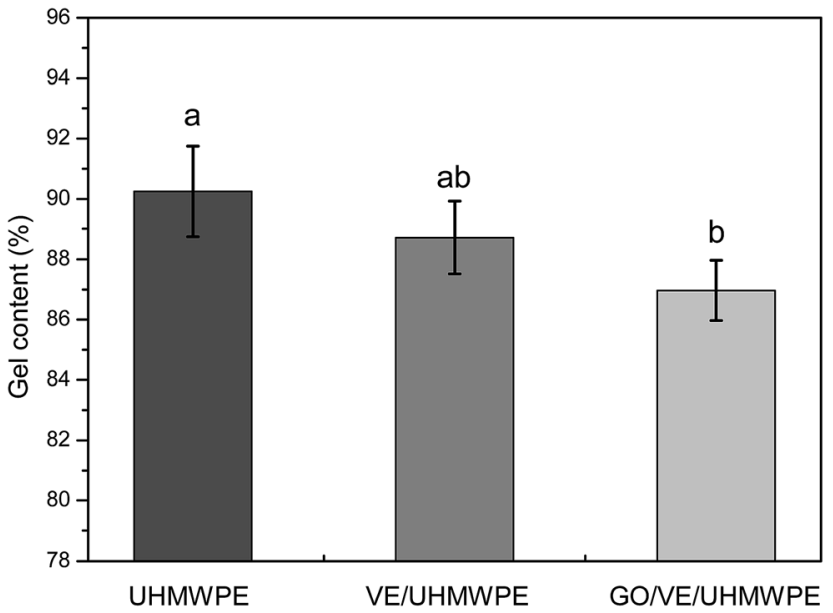

Fig. 6 Gel content of the irradiated samples. Error bars represent standard deviation. Different letters denote significant difference $(P<$ 0.05).

of vitamin-E, and it is similar to previous research. ${ }^{27}$ The gel content of irradiated GO/VE/UHMWPE composite is further reduced with the incorporation of GO. This may be that the mobility of chain scission is hindered by the strong interface binding force between GO and VE/UHMWPE matrix. In addition, Gonçalves et $a .^{28}$ and Kolanthai et al. ${ }^{29}$ demonstrate that $\mathrm{GO} /$ graphene has ability to scavenge free radicals to some extent. As a result, the incorporation of GO further reduces the crosslink density of GO/VE/UHMWPE nanocomposite.

\subsection{Mechanical properties}

Fig. 7 shows the micro-hardness of the samples. It can be found that the hardness of pure UHMWPE is weakened by adding of VE and the hardness of VE/UHMWPE blend is enhanced by adding of GO. This is due to the excellent mechanical properties of GO and the wrinkled two-dimensional structure can bear loads and transfer the loads to the layered structure. After irradiation treatment, the hardness of UHMWPE increases from 25.46 to 26.33 MPa due to the cross-linking effect during irradiation process. And the hardness of irradiated VE/UHMWPE blend is $26.96 \mathrm{MPa}$ which indicates that the addition of VE has little significant influence on the hardness of irradiated UHMWPE. Although the addition of VE reduces the crosslinking degree of irradiated UHMWPE, VE still effectively improves the oxidation resistance during the irradiation process thus avoids the reduction of hardness due to oxidation and embrittlement. ${ }^{30}$ The joint action of two factors enables little significant change of the hardness of irradiated VE/ UHMWPE. The hardness of irradiated GO/VE/UHMWPE composite reach at 27.64 MPa after adding GO. It is indicated that the addition of GO slightly improves the hardness of irradiated VE/UHMWPE blend. The irradiated GO/VE/UHMWPE possesses the optimal hardness because of irradiation treatment and GO. Buchanan et al. ${ }^{31}$ report that the hardness of material is directly related to its crystallinity and the hardness increases gradually with increasing crystallinity. It is similar to

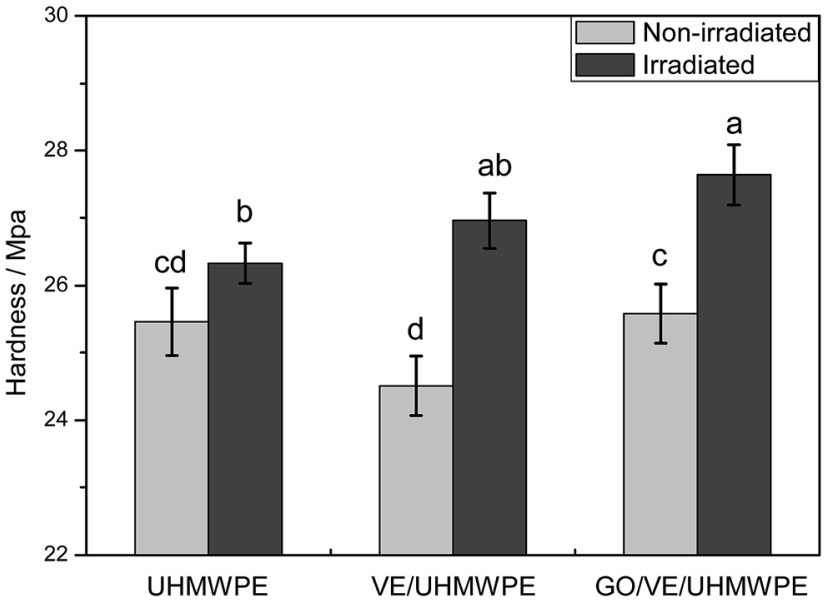

Fig. 7 The micro-hardness of the composites. Error bars represent standard deviation. Different letters denote significant difference $(P<$ 0.05)

the results of this study. Although the addition of GO slightly reduces the crosslinking degree of irradiated VE/UHMWPE blend, the addition of GO still increases the hardness of irradiated VE/UHMWPE blend. It is indicated that the crystallinity and GO play a dominant role in improving the hardness of composites.

As shown in Fig. 8, the tensile properties (Young modulus, yield stress, fracture stress) show little significant change with the incorporation of vitamin-E, compare to that of virgin UHMWPE before and after irradiation. These results are consistent with previous studies. ${ }^{\mathbf{6} 31}$ Fortunately, the mechanical properties are dramatically improved with the incorporation of GO. The Young modulus is increased by 19.93\%, from 357.41 Mpa to 428.67 Mpa, compares to that of VE/UHMWPE blend (Fig. 8a). As discussed above, GO possesses huge specific surface area and abundant polarity oxygen containing functional groups on the surface and margin, which could result in powerful interface interactions between GO and polymer matrix. The powerful interface interactions cooperate with the inherent high hardness of GO lead to an increase in Young modulus. In addition, the increased crystallinity of GO/VE/UHMWPE also promotes the increase in Young modulus.

In general, yield stress appears to be associated with crystallinity of composites. ${ }^{32}$ In present study, the yield stress is improved obviously with the filler of GO into VE/UHMWPE composite (Fig. 8b). The obtained results are consistent with the variation trend of crystallinity of GO/VE/UHMWPE composite. Moreover, GO could transfer load from polymer matrix to GO. Hence, the increased yield stress can be associated to the enhancement effect of GO. On the other hand, the incorporation of GO also has a significant effect on the fracture stress which is increased by $16.96 \%$ (Fig. 8c). This result also confirm the powerful interface interactions between GO and VE/ UHMWPE matrix. As shown in Fig. 8d, the addition of VE has little effect on the maximum strain of UHMWPE. And there is a decrease in maximum strain of samples with irradiated 

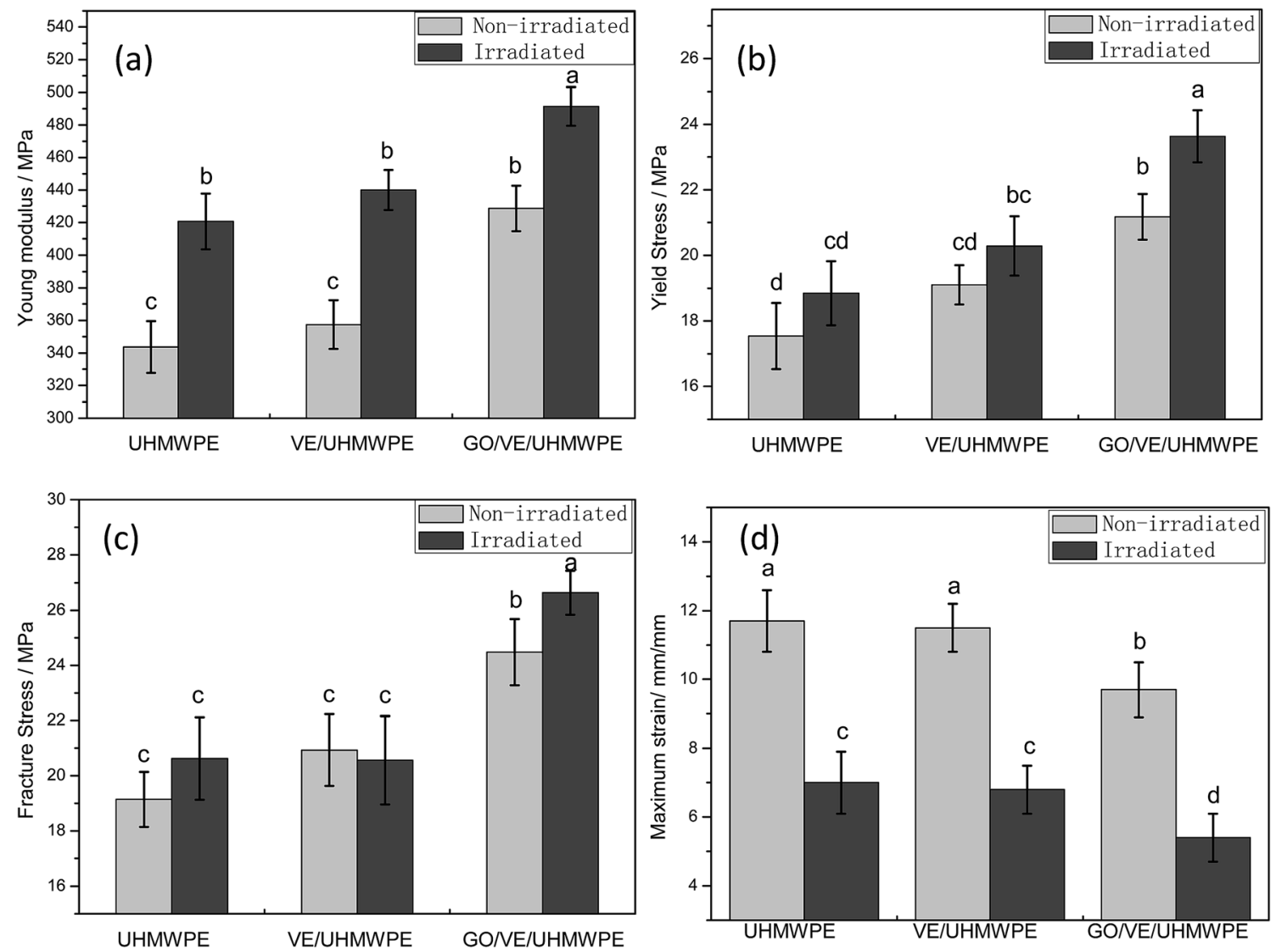

Fig. 8 The tensile properties of the composites: (a) Young modulus; (b) yield stress; (c) fracture stress; (d) maximum strain. Error bars represent standard deviation. Different letters denote significant difference $(P<0.05)$.

treatment. However, it should be mentioned that the maximum strain decreased once GO is added into the UHMWPE/VE blend.

In this work, we also characterize the influence of irradiation on mechanical properties of all the studied specimens. The results show that, the young modulus, yield stress and fracture stress of samples are further increased to some extent after irradiation. On one hand, this is because of the strong interfacial interactions improved by irradiation crosslinking. Irradiation could result in cleavage of $\mathrm{C}-\mathrm{C}$ and $\mathrm{C}-\mathrm{H}$ bond, and generates free radicals which can recombine with each other to form molecular bonds and increases the interface interactions. Moreover, Kolanthai et al. ${ }^{29}$ investigates the effect of graphene on the mechanical properties of UHMWPE/LLDPE (linear lowdensity polyethylene)/graphene. The results show that both irradiation and the filler of graphene could enhance the interfacial interactions between graphene and UHMWPE/LLDPE matrix. On the other hand, further increased crystallinity of all studied samples is observed after irradiation, which is a crucial factor to mechanical properties. Thus, the irradiation result in improved mechanical properties compared to nonirradiated UHMWPE based composites.

Generally speaking, surface hardness is also a critical factor to wear resistance. Ge et al. ${ }^{33}$ show that the plastic contact areas between polymer matrix and metal friction pair would be decreased with increasing hardness. The hardness of non- irradiated VE/UHMWPE blend is reduced slightly compared to virgin UHMWPE. Fortunately, the hardness is improved with the incorporation of GO. This mainly due to the transferring load performance of GO. In addition, the increased crystallinity of GO/VE/UHMWPE composite also plays an important role in improved hardness. According to the prediction of Buchanan, ${ }^{31}$ the hardness increases with the increasing crystallinity. After irradiation, the hardness of UHMWPE is enhanced dramatically, because of the increase of crystallinity and crosslinking density. Although, the crosslinking density is decreased slightly with the incorporation of $\mathrm{GO}$, the hardness of irradiated $\mathrm{GO} / \mathrm{VE} /$ UHMWPE composite increases all the same compares to that of irradiated VE/UHMWPE blend. This indicates that the performance of GO and crystallinity play dominant roles.

Table 2 summarizes the percentage variation of mechanical properties of similar irradiated and non-irradiated UHMWPEbased composites with respect to the virgin UHMWPE. Comparing the results of mechanical properties presented here with those for other irradiated and non-irradiated filler/ UHMWPE composites in the literatures, ${ }^{19,34,35}$ it becomes evident that only a very small amount of GO can significantly improve the mechanical properties of UHMWPE. In the Table 2, the contents of fillers are optimal for effective enhancement of mechanical properties. For common fillers such as CNT and HAP, a relatively high content of filler is needed to effectively 
Table 2 Percentage variation of mechanical properties of similar irradiated and non-irradiated composites with respect to the virgin UHMWPE ${ }^{a}$

\begin{tabular}{|c|c|c|c|c|c|}
\hline Composites & $\begin{array}{l}\text { Filler fraction } \\
(\mathrm{wt} \%)\end{array}$ & $\begin{array}{l}\text { Young's } \\
\text { modulus (MPa) }\end{array}$ & $\begin{array}{l}\text { Yield stress } \\
\text { (MPa) }\end{array}$ & $\begin{array}{l}\text { Fracture stress } \\
(\mathrm{MPa})\end{array}$ & Ref. \\
\hline CNT/UHMWPE & 3 & $37.9 \%$ & $4 \%$ & $7.9 \%$ & 34 \\
\hline GO/UHMWPE & 0.5 & $12.4 \%$ & $11.9 \%$ & $24.4 \%$ & 19 \\
\hline GO/UHMWPE-I (75 kGy) & 0.5 & $18.2 \%$ & $17.1 \%$ & $1 \%$ & 19 \\
\hline HAP/UHMWPE & $1 \%$ & $5.3 \%$ & & $-43.4 \%$ & 35 \\
\hline GO/VE/UHMWPE-I (100 kGy) & $0.5 / 0.1$ & $39 \%$ & $32.7 \%$ & $38.1 \%$ & This work \\
\hline
\end{tabular}

${ }^{a} \mathrm{CNT}$ : carbon nanotubes; HAP: hydroxyapatite.

improve the mechanical properties. $^{34,35}$ In contrast, the mechanical properties can be significantly improved by the incorporation of GO with a much lower content. ${ }^{19}$ As shown in Table 2, irradiation further improved the mechanical properties of both CNT/UHMWPE and GO/UHMWPE. Compares with irradiated CNT/UHMWPE, the irradiated GO/VE/UHMWPE possesses the similar mechanical properties with much low fillers amount.

\subsection{Postulated enhancement mechanism}

The mechanical properties (tensile properties and surface hardness) of irradiated and non-irradiated GO/VE/UHMWPE composite are enhanced with the incorporation of GO to some extent. Similarly to previous studies, ${ }^{16,17,28}$ the mechanical properties of polymer are improved with the incorporation of carbonaceous particles such as graphene and GO. We attribute the enhancement mechanism of GO enhanced polyethylenebased composites to the following effects: ${ }^{16}$ (a) the welldispersion and performance of transferring load of GO due to the huge specific surface area; (b) the excellent mechanical properties of graphene oxide itself, and the increased crystallinity due to the effect of nucleation of GO; (c) the interaction force between GO and UHMWPE matrix through van der Waals' force. The enhancement mechanism of composite prior to irradiation is similar to that of our previous study. ${ }^{\mathbf{1 6}}$ Different from our previous study which just focuses on the effect of adding GO into UHMWPE, ${ }^{\mathbf{1 6}}$ the GO/UHMWPE composite are exposed to irradiation treatment and VE is added to improve the oxidation resistance of irradiated composite in this paper.

In early studies, Shen et $a .^{36}$ reports that irradiation produces crosslinking in amorphous regions and wear is observed to be much lower for chemically crosslinked cups. Perez and Vanderhart ${ }^{37}$ also report that irradiation induced crosslink formation and produced Y-type branches and H-type branches. In addition, Kolanthai et al. ${ }^{29}$ reports that GO could graft on polymer chains during the irradiation process, and then the interactions at polymer-graphene interface are enhanced. Anson-Casaos et al. ${ }^{38}$ reports that graphene materials could role as radical scavengers and crosslinking generators. Based on the above reports, a postulated enhancement

(a)

(b)
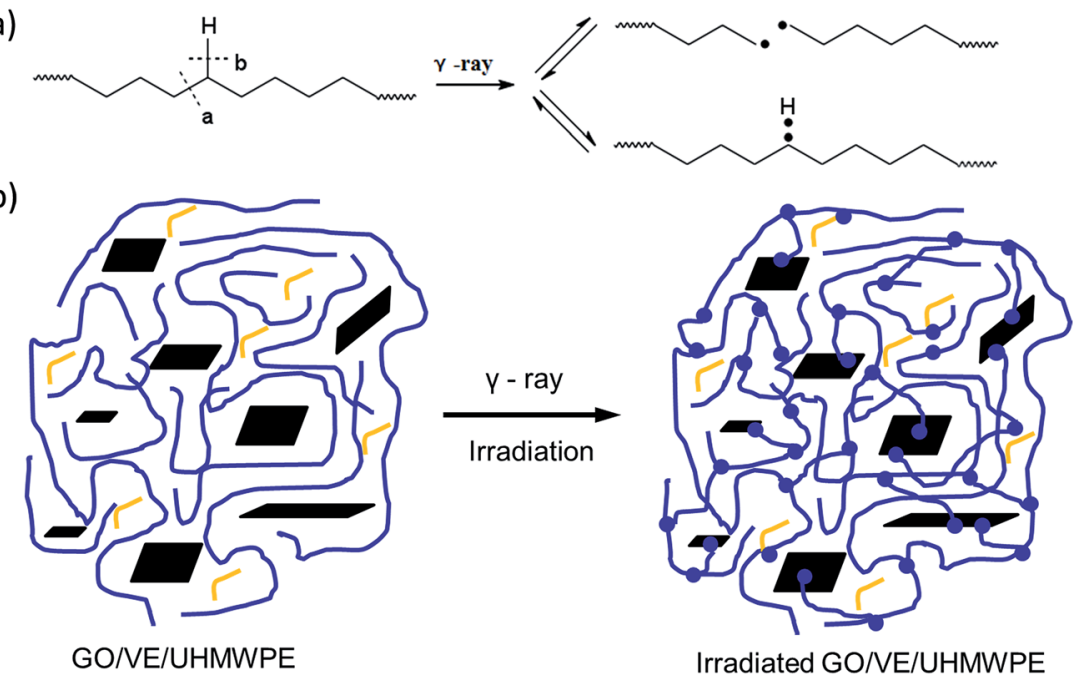

SUHMWPE $\approx$ Go Vitamin E

Fig. 9 Mechanism of radical formation during irradiation (a) and enhancement mechanism of composite with irradiation and without irradiation (b). 
mechanism of irradiated GO/VE/UHMWPE composite is established, as shown in Fig. 9. Irradiation treatment results in the breaking of $\mathrm{C}-\mathrm{C}$ bonds and $\mathrm{C}-\mathrm{H}$ bonds of UHMWPE and then forms free radicals, as shown in Fig. 9a. The breaking of $\mathrm{C}-\mathrm{C}$ bonds in irradiated materials is a random process, and the broken $\mathrm{C}-\mathrm{C}$ bonds recombine to form new $\mathrm{C}-\mathrm{C}$ bonds. The conjugated double bonds which consist in carbon nanostructures give carbon nanomaterials a great ability of electron donor-acceptor. ${ }^{29,39}$ Therefore, irradiation crosslinking treatment not only enables UHMWPE molecule to form reticular structure, but also causes the broken $\mathrm{C}-\mathrm{C}$ bonds of $\mathrm{GO}$ to react with the broken $\mathrm{C}-\mathrm{C}$ bonds of UHMWPE to form new $\mathrm{C}-\mathrm{C}$ bonds, as shown in Fig. 9b. The $\mathrm{C}-\mathrm{C}$ chemical bonds between GO filler and UHMWPE matrix produce by irradiation treatment are much stronger than van der Waals' force between GO filler and UHMWPE matrix, ${ }^{16}$ which lead to more excellent mechanical properties of irradiated composite.

Moreover, VE is added into UHMWPE to improve the oxidation resistance of blends after irradiation treatment. The oxidation process of irradiated UHMWPE can be explained by the formation of free radicals and their subsequent reactions with oxygen. ${ }^{40}$ The formation of hydrocarbon groups in UHMWPE (Fig. 9a) and their reactions with oxygen are key steps in a series of oxidation processes. The hydrocarbon radicals react with oxygen to form peroxy group. These peroxy groups absorb hydrogen atoms from neighboring UHMWPE molecules and form hydrogen peroxide and new hydrocarbon radicals. Fortunately, the cyclic reactions described above are terminated because hydrogen atoms in VE replace hydrogen atoms in UHMWPE to combine with highly reactive free radicals $\mathrm{COO}^{\circ}$ to form stable compounds. Therefore, due to the absence of VE, the GO/VE/UHMWPE composite show well resistance to oxidation, which avoid the negative effects during irradiation process.

\section{Conclusion}

This work has focused on the mechanical enhancement of graphene oxide nanoparticles and the oxidation resistance of VE on the properties of irradiated UHMWPE. Incorporation of GO into vitamin E-blends of UHMWPE prior to radiation crosslinking offers a feasible method of improving the mechanical properties of irradiated vitamin E-blends while obtaining high micro-hardness, tensile properties and oxidation resistance. The following conclusions can be drawn:

(1) The incorporation of GO increases the crystallinity of GO/ VE/UHMWPE composite and the irradiation treatment further increases the crystallinity.

(2) Tensile properties and micro-hardness of GO/VE/ UHMWPE composite are improved by adding of GO due to the excellent mechanical properties of GO. And the addition of VE improves the oxidation resistance of composite.

(3) Mechanical properties of GO/VE/UHMWPE composite are further improved after irradiation treatment because new $\mathrm{C}-\mathrm{C}$ chemical bonds are generated between GO filler and UHMWPE matrix to improve combining power between filler and matrix. Meanwhile, the effects of oxidation resistance of $\mathrm{VE}$ and irradiation cross-linking of UHMWPE molecular chain are also essential. The GO/VE/UHMWPE composite may enable the use of cross-linked blends in total joint implants in more mechanically demanding applications.

However, there are some limitations in this study. For example, the fracture toughness, fatigue strength, resistance to delamination and wear resistance of the material are not reported, even though they are key mechanical properties for implant applications. And they should to be further studied in the future.

\section{Conflicts of interest}

There are no conflicts to declare.

\section{Acknowledgements}

This work was supported by the National Natural Science Foundation of China [Grant no. 51305166, 51675232], the Natural Science Foundation of Jiangsu Province, China [BK20130143] and Natural Science Foundation of Shandong Province, China [ZR2017PA008].

\section{References}

1 O. K. Muratoglu, C. R. Bragdon, D. O. O'Connor, M. Jasty and W. H. Harris, A novel method of cross-linking ultra-highmolecular-weight polyethylene to improve wear, reduce oxidation, and retain mechanical properties. Recipient of the 1999 HAP Paul Award, J. Arthroplasty, 2001, 16, 149-160.

2 P. Bracco, E. M. B. D. Prever, M. Cannas, M. P. Luda and L. Costa, Oxidation behaviour in prosthetic UHMWPE components sterilised with high energy radiation in a lowoxygen environment, Polym. Degrad. Stabil., 2006, 91, 20302038.

3 L. Costa, P. Bracco, E. M. B. D. Prever, S. M. Kurtz and P. Gallinaro, Oxidation and oxidation potential in contemporary packaging for polyethylene total joint replacement components, J. Biomed. Mater. Res., Part B, 2006, 78, 20-26.

4 S. M. Kurtz, W. J. Hozack, J. J. Purtill, M. Marcolongo, M. J. Kraay, V. M. Goldberg, et al., 2006 Otto Aufranc Award Paper: significance of in vivo degradation for polyethylene in total hip arthroplasty, Clin. Orthop. Relat. Res., 2006, 453, 47-57.

5 F. J. Medel, P. Pena, J. Cegonino, E. Gomez-Barrena and J. A. Puertolas, Comparative fatigue behavior and toughness of remelted and annealed highly crosslinked polyethylenes, J. Biomed. Mater. Res., Part B, 2007, 83, 380390.

6 E. Oral, K. K. Wannomae, S. L. Rowell and O. K. Muratoglu, Migration stability of alpha-tocopherol in irradiated UHMWPE, Biomaterials, 2006, 27, 2434-2439.

7 E. Oral, E. S. Greenbaum, A. S. Malhi, W. H. Harris and O. K. Muratoglu, Characterization of irradiated blends of $\alpha$ tocopherol and UHMWPE, Biomaterials, 2005, 26, 66576663. 
8 S. M. Kurtz, J. Dumbleton, R. S. Siskey, A. Wang and M. Manley, Trace concentrations of vitamin E protect radiation crosslinked UHMWPE from oxidative degradation, J. Biomed. Mater. Res., Part A, 2009, 90, 549-563.

9 C. Wolf, T. Krivec, J. Blassnig, K. Lederer and W. Schneider, Examination of the suitability of $\alpha$-tocopherol as a stabilizer for ultra-high molecular weight polyethylene used for articulating surfaces in joint endoprostheses, J. Mater. Sci.: Mater. Med., 2002, 13, 185-189.

10 E. Oral, B. W. Ghali, S. L. Rowell, B. R. Micheli, A. J. Lozynsky and O. K. Muratoglu, A surface crosslinked UHMWPE stabilized by vitamin $\mathrm{E}$ with low wear and high fatigue strength, Biomaterials, 2010, 31, 7051-7060.

$11 \mathrm{~J} . \mathrm{Fu}$, B. N. Doshi, E. Oral and O. K. Muratoglu, High temperature melted, radiation cross-linked, vitamin $\mathrm{E}$ stabilized oxidation resistant UHMWPE with low wear and high impact strength, Polymer, 2013, 54, 199-209.

12 C. Lee, X. D. Wei, J. W. Kysar and J. Hone, Measurement of the elastic properties and intrinsic strength of monolayer graphene, Science, 2008, 321, 385-388.

13 A. K. Geim, Graphene:status and prospects, Science, 2009, 324, 1530-1534.

$14 \mathrm{X}$. Zhou and F. Liang, Application of graphene/graphene oxide in biomedicine and biotechnology, Curr. Med. Chem., 2013, 21, 855-869.

15 C. N. Rao, A. K. Sood, K. S. Subrahmanyam and A. Govindaraj, Graphene: the new two-dimensional nanomaterial, Angew. Chem., Int. Ed., 2009, 48, 7752-7777.

16 W. Pang, Z. Ni, G. Chen, G. Huang, H. Huang and Y. Zhao, Mechanical and thermal properties of graphene oxide/ ultrahigh molecular weight polyethylene nanocomposites, RSC Adv., 2015, 5, 63063-63072.

17 Y. Chen, Y. Qi, Z. Tai, X. Yana and Q. Xue, Preparation, mechanical properties and biocompatibility of graphene oxide/ultrahigh molecular weight polyethylene composites, Eur. Polym. J., 2012, 48, 1026-1033.

18 Z. Tai, Y. Chen, Y. An, X. Yan and Q. Xue, Tribological Behavior of UHMWPE Reinforced with Graphene Oxide Nanosheets, Tribol. Lett., 2012, 46, 55-63.

19 S. Suñer, R. Joffe, J. L. Tipper and N. Emami, Ultra high molecular weight polyethylene/graphene oxide nanocomposites: Thermal, mechanical and wettability characterisation, Composites, Part B, 2015, 78, 185-191.

20 W. S. Hummers and R. E. Offeman, Preparation of graphitic oxide, J. Am. Chem. Soc., 1958, 80, 1339.

21 L. Xiong and D. S. Xiong, The influence of irradiation dose on the mechanical properties and wear resistance of molded and extruded ultra high molecular weight polyethylene, J. Mech. Behav. Biomed. Mater., 2012, 9, 73-82.

22 F. J. Buchanan, B. Sim and S. Downes, Influence of packaging conditions on the properties of gammairradiated UHMWPE following accelerated ageing and shelf ageing, Biomaterials, 1999, 20, 823-837.

23 B. R. Burroughs and T. A. Blanchet, The effect of preirradiation vacuum storage on the oxidation and wear of radiation sterilized UHMWPE, Wear, 2006, 261, 1277-1284.
24 K. K. Wannomae, S. Bhattacharyya, A. Freiberg, D. Estok, W. H. Harris and O. Muratoglu, In vivo oxidation of retrieved cross-linked ultra-high molecular weight polyethylene acetabular components with residual free radicals, J. Arthroplasty, 2006, 21, 1005-1011.

25 V. Premnath, W. H. Harris, M. Jasty and E. W. Merrill, Gamma sterilization of UHMWPE articular implants: an analysis of the oxidation problem. Ultra High Molecular Weight Poly Ethylene, Biomaterials, 1996, 17, 1741-1753.

26 H. Wang, L. Xu, J. Hu, M. Wang and G. Wu, Radiationinduced oxidation of ultra-high molecular weight polyethylene (UHMWPE) powder by gamma rays and electron beams: A clear dependence of dose rate, Radiat. Phys. Chem., 2015, 115, 88-96.

27 E. Oral, B. C. Godleski, A. S. Malhi and O. K. Muratoglu, The effects of high dose irradiation on the cross-linking of vitamin E-blended ultrahigh molecular weight polyethylene, Biomaterials, 2008, 29, 3557-3560.

28 G. Gonçalves, S. M. Cruz, A. Ramalho, J. Grácio and P. A. Marques, Graphene oxide versus functionalized carbon nanotubes as a reinforcing agent in a PMMA/HA bone cement, Nanoscale, 2012, 4, 2937-2945.

29 E. Kolanthai, S. Bose, K. S. Bhagyashree, S. V. Bhat, K. Asokan, D. Kanjilal and K. Chatterjee, Graphene scavenges free radicals to synergistically enhance structural properties in a gamma-irradiated polyethylene composite through enhanced interfacial interactions, Phys. Chem. Chem. Phys., 2015, 17, 22900-22910.

30 Y. Pei, D. Xie, Y. Leng, L. Qian, H. Sun and N. Huang, Effects of screen-grid bias voltage on the microstructure and properties of the ultrahigh molecular weight polyethylene (UHMWPE) modified by oxygen plasma, Vacuum, 2012, 86, 1945-1951.

31 F. J. Buchanan, J. R. White, B. Sim and S. Downes, The influence of gamma irradiation and aging on degradation mechanisms of ultra-high molecular weight polyethylene, J. Mater. Sci.: Mater. Med., 2001, 12, 29-37.

32 A. Galeski, Strength and toughness of crystalline polymer systems, Prog. Polym. Sci., 2003, 28, 1643-1699.

33 S. Ge, S. Wang and X. Huang, Increasing the wear resistance of UHMWPE acetabular cups by adding natural biocompatible particles, Wear, 2009, 267, 770-776.

34 M. J. Martinez-Morlanes, P. Castell, V. Martinez-Nogues, M. T. Martinez, P. J. Alonso and J. A. Puertolas, Effects of gamma-irradiation on UHMWPE/MWNT nanocomposites, Compos. Sci. Technol., 2011, 71, 282-288.

35 L. Xiong, D. S. Xiong, Y. Y. Yang and J. B. Jin, Friction, wear, and tensile properties of vacuum hot pressing crosslinked UHMWPE/nano-HAP composites, J. Biomed. Mater. Res., Part B, 2011, 98, 127-138.

36 F. W. Shen, H. A. Mckellop and R. Salovey, Irradiation of chemically crosslinked ultrahigh molecular weight polyethylene, J. Polym. Sci., Part B: Polym. Phys., 1996, 34, 1063-1077.

37 E. Perez and D. L. Vanderhart, ${ }^{13} \mathrm{C}$ CP-MAS NMR study of irradiated polyethylene, J. Polym. Sci., Part B: Polym. Phys., 1988, 26, 1979-1993. 
38 A. Anson-Casaos, J. A. Puertolas, F. J. Pascual, J. HernandezFerrer, P. Castell, A. M. Benito, W. K. Maser and M. T. Martinez, The effect of gamma-irradiation on fewlayered graphene materials, Appl. Surf. Sci., 2014, 301, 264272.
39 A. Galano, Carbon nanotubes: promising agents against free radicals, Nanoscale, 2010, 2, 373-380.

40 L. Costa and P. Bracco, UHMWPE Biomaterials Handbook, 3rd edn, 2015. 